\title{
A highly sensitive fluorometric assay for the determination of glutathione reductase activity
}

\author{
Andrew M. Piggott and Peter Karuso* \\ Department of Chemistry \& Biomolecular Sciences, Macquarie University, Sydney, NSW, 2109, Australia
}

\section{TABLE OF CONTENTS}

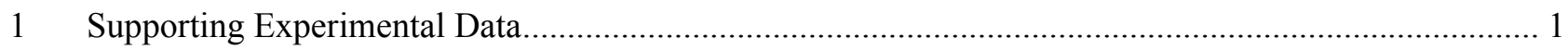

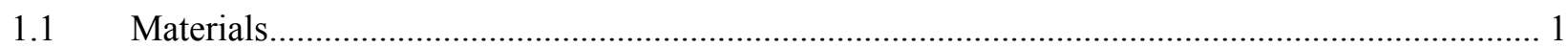

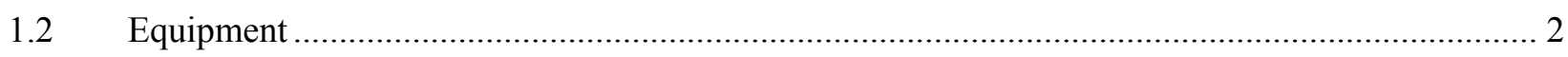

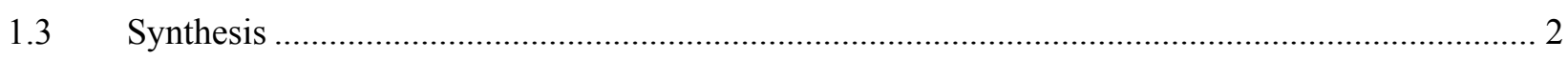

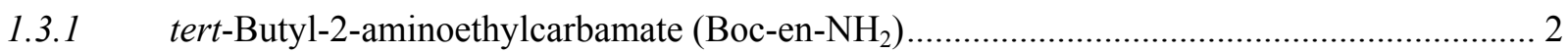

1.3.2 3,3'-Dithiodipropionic acid 2-tert-butoxycarbonylaminoethylamide (1).............................. 3

1.3.3 3,3'-Dithiodipropionic acid (5/6-fluoresceinylcarbonylaminoethyl)-amide (2)..................... 3

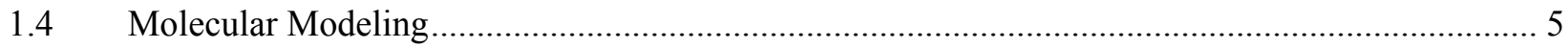

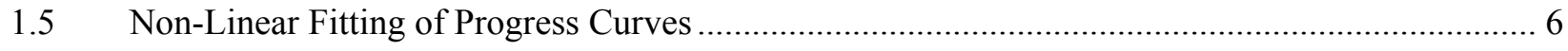

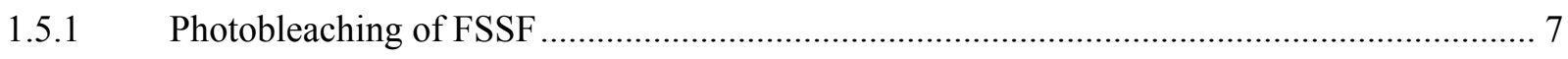

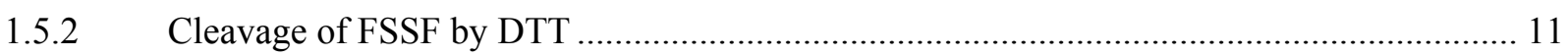

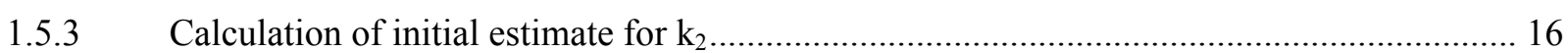

1.5.4 Comparison of fluorometric assay with commercial colorimetric (DTNB) GR assay.......... 21

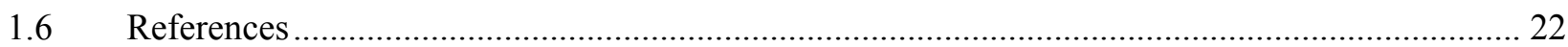

\section{Supporting Experimental Data}

\subsection{Materials}

Di-tert-butyldicarbonate and 3,3'-dithiodipropionic acid were obtained from Fluka (Switzerland). Acetonitrile, ammonium chloride and hydrochloric acid were obtained from BDH/Merck (Germany). DMSO was obtained from Riedel-de-Haën (Germany). Bulk solvents were obtained from Fronine (Australia). NHS-fluorescein was obtained from Pierce (USA). All other reagents were obtained from Aldrich (USA). Ethanol, ethyl acetate and methanol were distilled from 
anhydrous potassium carbonate. Acetonitrile and dichloromethane were distilled under nitrogen from calcium hydride. Chloroform was distilled under nitrogen from phosphorus pentoxide and stored in a dark bottle over silver wire. DMSO was dried over microwave-activated $4 \AA$ molecular sieves. All other solvents and reagents were used without further purification.

\subsection{Equipment}

NMR spectra were recorded in $5 \mathrm{~mm}$ Pyrex tubes (Wilmad, USA) on a DPX-400 $400 \mathrm{MHz}$ spectrometer (Bruker, Germany). IR spectra were recorded on a Paragon PE1000 FTIR spectrometer (Perkin Elmer, USA). UV-Vis spectra were recorded on a Cary 1-Bio spectrophotometer (Varian, USA) in $1 \mathrm{~cm}$ matched quartz cuvettes (Selbys Scientific, Australia). Melting points were determined using a digital melting point apparatus (Gallenkamp, UK) in open glass capillaries, and are uncorrected. High resolution ESI mass spectrometry was performed on an APEXII Fourier transform ion cyclotron resonance spectrometer (Bruker, Germany). HPLC was performed using a 600E multisolvent delivery system and a 490 programmable multiwavelength detector (Waters, USA), with a Gemini $250 \times 10 \mathrm{~mm}$ (semi-preparative) C18 HPLC column (Phenomenex, Australia). Small-scale distillation was performed by Kugelrohr (Büchi, Switzerland). Water was purified using a Milli-Q Ultrapure Water Purification System (Millipore, USA).

\subsection{Synthesis}

\subsection{1 tert-Butyl-2-aminoethylcarbamate (Boc-en- $\left.\mathrm{NH}_{2}\right)$}

A solution of di-tert-butyldicarbonate $(9.1 \mathrm{~g}, 42 \mathrm{mmol})$ in DCM $(50 \mathrm{~mL})$ was added dropwise, with vigorous stirring, to a solution of ethylenediamine (2.5 g, $42 \mathrm{mmol})$ in DCM (50 mL), during which time a white precipitate formed. The precipitate was collected at the pump and washed with icecold DCM (25 mL), yielding crude Boc-en-Boc as a white powder, which was not further purified (3.5 g, 64\%). m.p. $137-138^{\circ} \mathrm{C}$ (Lit. $\left.{ }^{1} 139-140{ }^{\circ} \mathrm{C}\right) .{ }^{1} \mathrm{H}-\mathrm{NMR}\left(400 \mathrm{MHz}, \mathrm{CDCl}_{3}, 25{ }^{\circ} \mathrm{C}\right) \delta 6.69$ (bs, $2 \mathrm{H}, 2 \times \mathrm{NHCO}), 2.90\left(\mathrm{~s}, 4 \mathrm{H}, 2 \times \mathrm{CH}_{2}\right), 1.34\left(\mathrm{~s}, 18 \mathrm{H}, 6 \times \mathrm{CH}_{3}\right)$.

A solution of the crude Boc-en-Boc $(3.0 \mathrm{~g}, 12 \mathrm{mmol})$ and TFA $(1.0 \mathrm{~mL}, 13 \mathrm{mmol})$ in DCM $(50 \mathrm{~mL})$ was refluxed gently for $18 \mathrm{~h}$. The solution was then extracted with aqueous ammonium chloride (1 $\mathrm{M} ; \mathrm{pH} 5 ; 3 \times 25 \mathrm{~mL})$ and the combined aqueous layers adjusted to $\mathrm{pH} 13(\mathrm{NaOH})$ and extracted with DCM $(3 \times 25 \mathrm{~mL})$. The combined organic layers were dried over anhydrous magnesium 
sulfate and reduced to dryness in vacuo to give a cloudy yellow oil. The oil was purified by Kügelrohr distillation $\left(95-100{ }^{\circ} \mathrm{C} ; 0.1 \mathrm{mmHg}\right.$ ) yielding Boc-en- $\mathrm{NH}_{2}$ as a colourless, viscous oil (1.6 g, 80\%). $\quad{ }^{1} \mathrm{H}-\mathrm{NMR}\left(400 \mathrm{MHz}, \mathrm{CDCl}_{3}, 25^{\circ} \mathrm{C}\right) \delta 5.06$ (bs, $\left.1 \mathrm{H}, \mathrm{NHCO}\right), 3.10$ (q, 2H, $\left.\mathrm{C}_{2} \mathrm{NHCO}\right), 2.73\left(\mathrm{t}, 2 \mathrm{H}, \underline{\mathrm{CH}}_{2} \mathrm{NH}_{2}\right), 1.39\left(\mathrm{~s}, 9 \mathrm{H}, 3 \times \mathrm{CH}_{3}\right), 1.22\left(\mathrm{bs}, 2 \mathrm{H}, \mathrm{NH}_{2}\right)$.

\subsubsection{3,3'-Dithiodipropionic acid 2-tert-butoxycarbonylaminoethylamide (1)}

A solution of 3,3'-dithiodipropionic acid (100 $\mathrm{mg}, 0.476 \mathrm{mmol})$, tert-butyl-2-aminoethylcarbamate (152 mg, $0.951 \mathrm{mmol})$, EDC (182 mg, $0.951 \mathrm{mmol})$ and TEA (100 mg, $0.990 \mathrm{mmol})$ in chloroform $(50 \mathrm{~mL})$ was stirred at room temperature for $18 \mathrm{~h}$. The reaction mixture was then washed with hydrochloric acid $(0.05 \mathrm{M} ; 2 \times 50 \mathrm{~mL})$ and water $(1 \times 50 \mathrm{~mL})$, dried over anhydrous magnesium sulfate and reduced to dryness in vacuo, yielding Boc-en-S-S-en-Boc 1 as a white powder (200 mg,

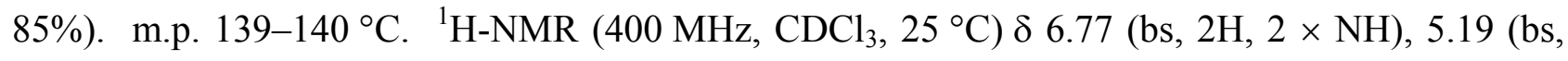
$2 \mathrm{H}, 2 \times \mathrm{NH}), 3.38\left(\mathrm{q}, 4 \mathrm{H}, 2 \times \mathrm{CH}_{2} \mathrm{~N}, J=5.0 \mathrm{~Hz}\right), 3.28\left(\mathrm{q}, 4 \mathrm{H}, 2 \times \mathrm{CH}_{2} \mathrm{~N}, J=5.0 \mathrm{~Hz}\right), 2.99(\mathrm{t}, 4 \mathrm{H}, 2$ $\left.\times \mathrm{CH}_{2} \mathrm{~S}, J=7.0 \mathrm{~Hz}\right), 2.58\left(\mathrm{t}, 4 \mathrm{H}, 2 \times \mathrm{CH}_{2} \mathrm{CO}, J=7.0 \mathrm{~Hz}\right), 1.44\left(\mathrm{~s}, 18 \mathrm{H}, 6 \times \mathrm{CH}_{3}\right) .{ }^{13} \mathrm{C}-\mathrm{NMR}$ $\left(100 \mathrm{MHz}, \mathrm{CDCl}_{3}, 25^{\circ} \mathrm{C}\right) \delta 171.7(\mathrm{C}=\mathrm{O}), 40.6\left(\mathrm{CH}_{2}\right), 40.2\left(\mathrm{CH}_{2}\right), 35.9\left(\mathrm{CH}_{2}\right), 34.6\left(\mathrm{CH}_{2}\right), 28.4$ $\left(\mathrm{CH}_{3}\right)$. Mass spectrum (HRESI+) m/z: $517.2119\left([\mathrm{M}+\mathrm{Na}]^{+}\right)$, calcd. for $\mathrm{C}_{20} \mathrm{H}_{38} \mathrm{~N}_{4} \mathrm{O}_{6} \mathrm{~S}_{2} \mathrm{Na}$ 517.2130. $\lambda_{\max }(\mathrm{MeCN}) 203,251 \mathrm{~nm}, \varepsilon$ 15700, $430 \mathrm{~L} \mathrm{~mol}^{-1} \cdot \mathrm{cm}^{-1}$. $v_{\max }(\mathrm{KBr} \operatorname{disc}) 3362(\mathrm{~s}), 3312(\mathrm{~s}), 3084(\mathrm{w})$, 2978(m), 2940(m), 1688(s), 1648(s), 1536(s), 1447(m), 1366(m), 1282(s), 1254(s), 1174(s), 877(m) $\mathrm{cm}^{-1}$.

\subsubsection{3,3'-Dithiodipropionic acid (5/6-fluoresceinylcarbonylaminoethyl)-amide (2)}

A solution of $1(10 \mathrm{mg}, 20 \mu \mathrm{mol})$ and TFA (1 mL) in anhydrous chloroform $(5 \mathrm{~mL})$ was stirred at room temperature for $30 \mathrm{~min}$ and then reduced to dryness under a stream of nitrogen, yielding the di-TFA salt of $\mathrm{H}_{2} \mathrm{~N}$-en-S-S-en- $\mathrm{NH}_{2}$ as a colorless oil (10 mg, 100\%), which was used immediately and not characterized further.

A solution of NHS-fluorescein (19 mg, $40 \mu \mathrm{mol}$; mixture of 5- and 6- isomers) and TEA (10 mg, $100 \mu \mathrm{mol})$ in ethanol $(10 \mathrm{~mL})$ was added to the oily residue and the solution was stirred at room temperature for $18 \mathrm{~h}$. The reaction mixture was then reduced to dryness under a stream of nitrogen and the resulting sticky orange residue was triturated with ethyl acetate $(5 \times 1 \mathrm{~mL})$, yielding crude 2 as a pale orange powder $(16 \mathrm{mg}, 82 \%)$. A small quantity $(2 \mathrm{mg})$ of the crude product was further 
purified by HPLC (Semi-prep C18 column, $3 \mathrm{~mL} / \mathrm{min}$, gradient from 10-100\% acetonitrile: water $+0.1 \%$ TFA over $40 \mathrm{~min}$ ), with a large UV-active peak (254 nm) eluting after $29 \mathrm{~min}$. This peak was collected and reduced to dryness under a stream of nitrogen, yielding pure FSSF 2 as a mixture of isomers. ${ }^{1} \mathrm{H}-\mathrm{NMR}\left(400 \mathrm{MHz}, \mathrm{DMSO}-d_{6}, 25^{\circ} \mathrm{C}\right) \delta 8.84(\mathrm{bs}, \mathrm{NH}), 8.71$ (bs, OH), 8.44 (m, Ar-H), 8.21 (m, Ar-H), 8.13 (m, Ar-H), 8.05 (m, Ar-H), 7.63 (s, Ar-H), 7.35 (d, Ar-H), 6.66 (m, Ar-H), $6.56(\mathrm{~m}, \mathrm{Ar}-\mathrm{H}), 6.54(\mathrm{~m}, \mathrm{Ar}-\mathrm{H}), 3.35\left(\mathrm{~m}, \mathrm{CH}_{2} \mathrm{~N}\right), 3.26\left(\mathrm{~m}, \mathrm{CH}_{2} \mathrm{~N}\right), 3.22\left(\mathrm{~m}, \mathrm{CH}_{2} \mathrm{~N}\right), 3.15(\mathrm{~m}$, $\left.\mathrm{CH}_{2} \mathrm{~N}\right), 2.84\left(\mathrm{~m}, \mathrm{CH}_{2} \mathrm{~S}\right), 2.43\left(\mathrm{~m}, \mathrm{CH}_{2} \mathrm{C}(\mathrm{O})\right) .{ }^{13} \mathrm{C}-\mathrm{NMR}\left(100 \mathrm{MHz}, \mathrm{DMSO}-d_{6}, 25{ }^{\circ} \mathrm{C}\right) \delta 134.3(\mathrm{Ar})$, 129.1 (Ar), 124.9 (Ar), 124.3 (Ar), 123.4 (Ar), 122.3 (Ar), 112.8 (Ar), 102.1 (Ar), $39.0\left(\mathrm{CH}_{2} \mathrm{~N}\right)$, $38.0\left(\mathrm{CH}_{2} \mathrm{~N}\right), 34.8\left(\underline{\mathrm{CH}_{2}} \mathrm{C}(\mathrm{O})\right), 33.4\left(\mathrm{CH}_{2} \mathrm{~S}\right)$. Mass spectrum $(\mathrm{HRESI}+) \mathrm{m} / z: 1033.2021\left([\mathrm{M}+\mathrm{Na}]^{+}\right)$, calcd. for $\mathrm{C}_{52} \mathrm{H}_{42} \mathrm{~N}_{4} \mathrm{O}_{14} \mathrm{~S}_{2} \mathrm{Na} 1033.2037$. $\lambda_{\max }(\mathrm{MeOH}) 240,474,500 \mathrm{~nm}, \varepsilon$ 77000, 51000, 120000 L.mol ${ }^{-1} \cdot \mathrm{cm}^{-1} . \quad v_{\max }(\mathrm{KBr}$ disc) 3410(br), 1740(m), 1646(s), 1608(s), 1548(s), 1504(m), 1461(s), 1388(m), 1322(m), 1249(m), 1180(m), 1113(m) $\mathrm{cm}^{-1}$.

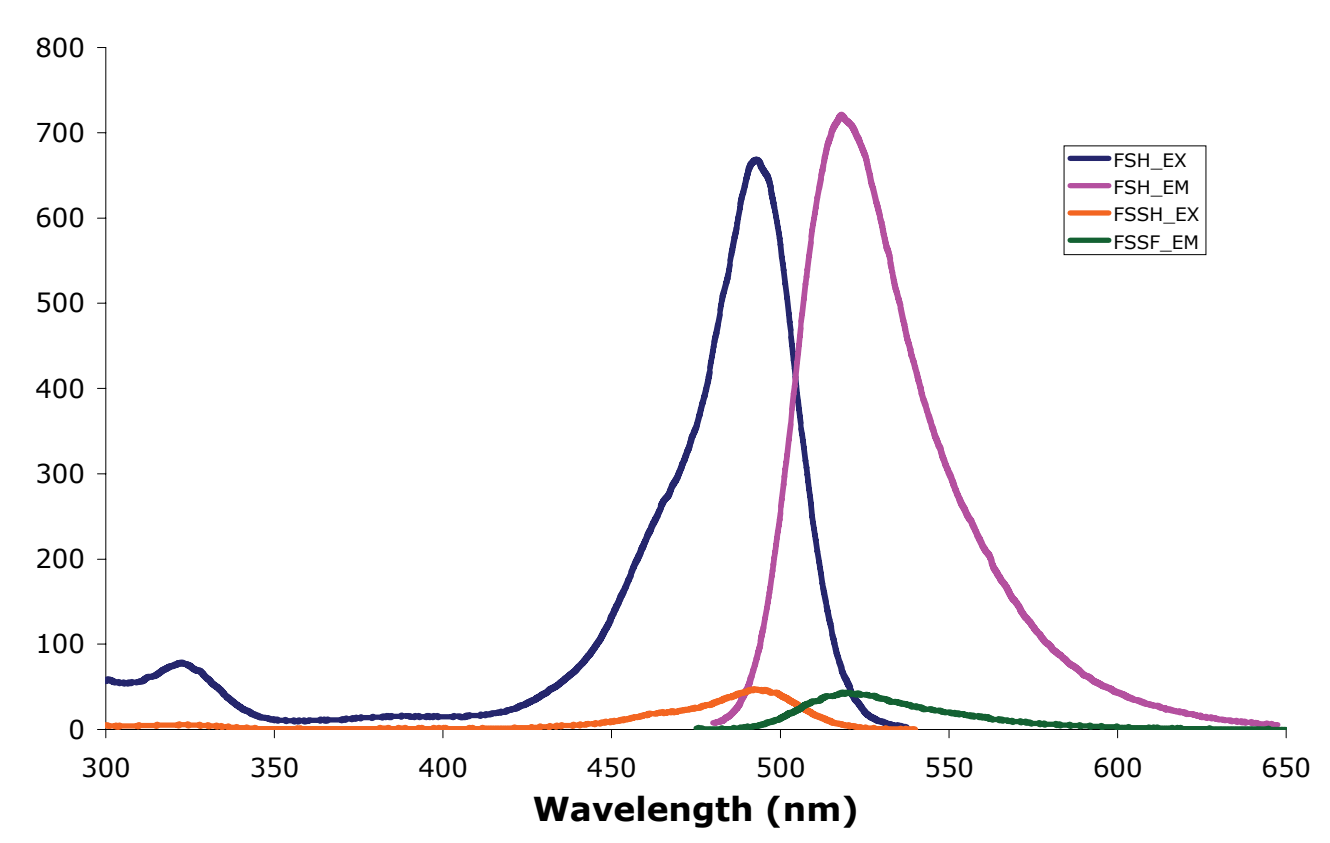

Figure S-0: Fluorescence excitation (orange) and emission (green) spectra for $100 \mathrm{ng} / \mathrm{mL}$ of FSSF (2) in phosphate buffered saline ( $\mathrm{pH} 7.5)$. After addition of $10 \mu \mathrm{g} / \mathrm{mL}$ DTT, the excitation (blue) and emission (magenta) spectra for the same sample measured again.

The FRET reduction in intensity for FSSF was measured to be $\sim 94 \%$ over two molecules of FSH. This figure correlates well with the theoretical efficiency of energy transfer given by equations (1) and (2). The rate of energy transfer $\left(k_{T}\right)$ over a distance $(r)$, is dependent on the fluorescence lifetime $\left(\tau_{\mathrm{D}}\right)$ and the Förster radius $\left(R_{0}\right)$. The efficiency of energy transfer, expressed as a fraction of full fluorescence is then given by (2). 
$k_{T}(r)=\frac{1}{\tau_{D}}\left(\frac{R_{0}}{r}\right)^{6}$

$E_{T}=\frac{k_{T}(r)}{\gamma+k_{T}(r)}$ where $\gamma=1 / \tau_{\mathrm{D}}$

For fluorescein/fluorescein donor/acceptor pairs, the Förster radius is $44 \AA$ (http://probes.invitrogen.com/handbook/boxes/0422.html) and the fluorescence lifetime is $\sim 4 \mathrm{~ns}$ (http://probes.invitrogen.com/handbook/boxes/1572.html). Thus for a separation of $30 \AA$ (Figure S1) a rate of transfer of $2.5 \mathrm{~ns}^{-1}$ is calculated. The efficiency of energy transfer is thus 0.91 , i.e. $9 \%$ of a single fluorescein molecule, which is in good agreement with the observed RET of 0.94 . The observed quenching corresponds to an average distance of $24 \AA$, which is completely reasonable considering that the linker is flexible but the amides and disulfide are likely to spend most of their time in a trans-orientation.

\subsection{Molecular Modeling}

A geometry optimized molecular model of FSSF (Figure S-1) was created using the Chem3D software package (Cambridgesoft, USA) running under Microsoft Windows XP. Energy minimization was performed using molecular mechanics (MM2 force field) with a conjugate gradient convergence method (minimum RMS gradient $=0.100$ ).

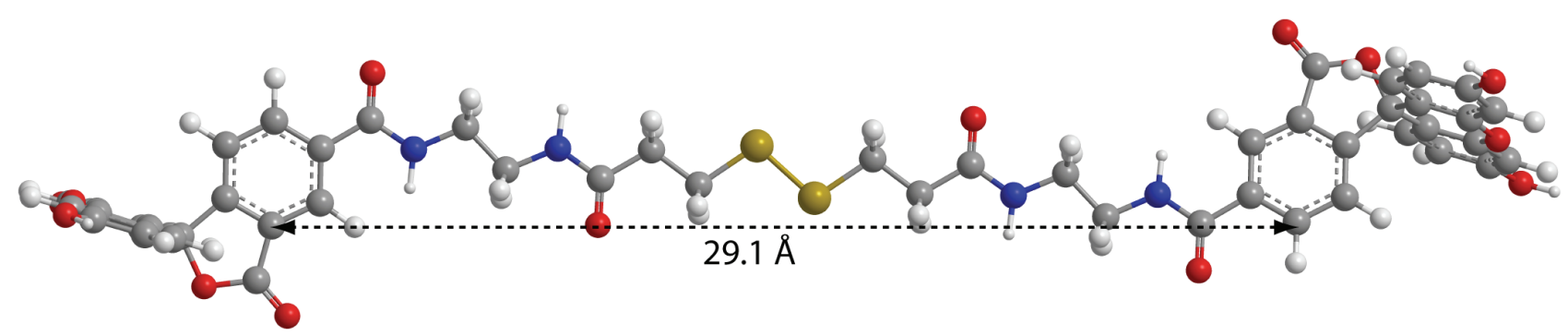

Figure S-1 - Geometry optimized (MM2) model of FSSF (2) showing that the maximum distance between the two fluorophores is less than $30 \AA$ when the disulfide-containing linker is fully extended. 


\subsection{Non-Linear Fitting of Progress Curves}

All non-linear least squares regressions in this study were performed using the Dynafit ${ }^{2}$ program (Biokin). Dynafit characterizes reacting system in terms of symbolic, or stoichiometric, equations. The names of chemical species are entirely arbitrary and can be freely chosen by the investigator. Our general approach was first to fit the data to the simplest model possible and then to introduce more complex terms, using the previously determined constants as starting points, to try and improve the fit. This led ultimately to the description of the FRET based GR assay as a fivecomponent system.

All input data for DynaFit are simple text files in the ASCII format arranged in columns (independent variable vs. dependent variable). Script files contain the description of the reaction mechanism, initial estimates of fitting parameters, and the location of experimental data files on the disk. Parameters followed by '??' are allowed to vary and are optimized by the least squares regression algorithm, while all other parameters are treated as constants. The "delay" parameter for each reaction refers to the difference (in seconds) between $t=0$ and the time when the reagents were mixed together to start the reaction. The "ConcError" parameter allows the concentrations of reagents to vary by a certain percentage to account for pipetting errors, which are unavoidable with small volumes, thereby improving the overall fit of the model.

The Dynafit "response factor" for a particular reagent refers to the change in signal (fluorescence at $520 \mathrm{~nm}$ in this case) observed when $1 \mu \mathrm{M}$ of that reagent is formed. For our analyses, we used two separate response factors - one for FSSF and one for FSH. The response factor for FSSF was calculated by measuring the fluorescence of a $1 \mu \mathrm{M}$ solution of FSSF at $520 \mathrm{~nm}$, while the response factor for FSH was determined by fitting the progress curve obtained from the cleavage of a $1 \mu \mathrm{M}$ solution of FSSF with $10 \mathrm{mM}$ DTT to an exponential equation and extrapolating out to infinity (Figure S-2). The response factors obtained vary slightly between experiments as different receiver gain settings were used on the fluorimeter on different days. 


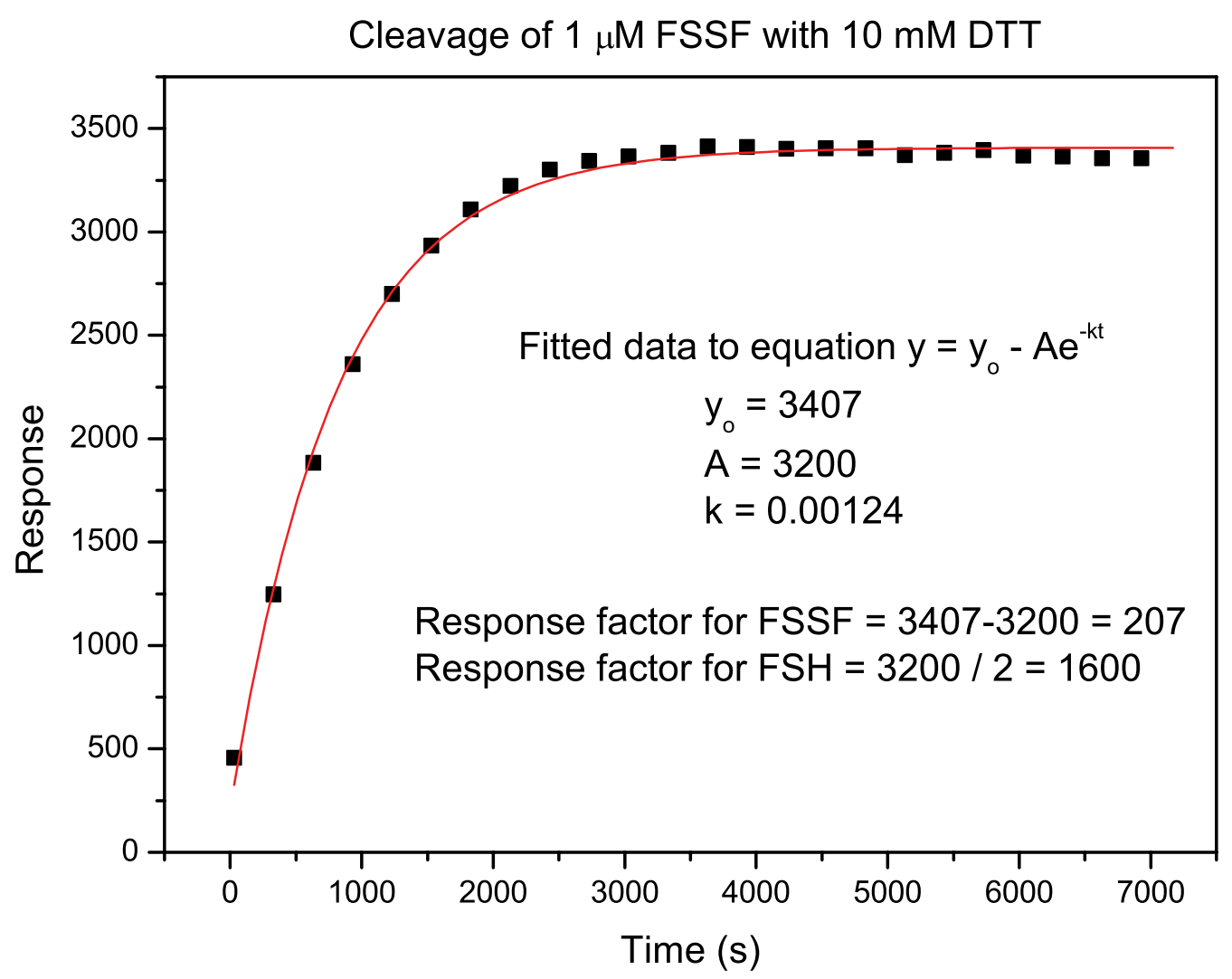

Figure S-2. Calculation of Dynafit response factors for FSSF and FSH.

\subsubsection{Photobleaching of FSSF}

Photobleaching occurs when a fluorophore permanently loses the ability to fluoresce due to photoninduced chemical damage. In this study, both the probe (FSSF) and product (FSH) were susceptible to photobleaching and hence the rates of photobleaching of both these species had to be determined and accounted for in subsequent Dynafit models. This can be observed in Figure S-2 as a slight drop in fluorescence after 4000 seconds. To calculate the rate of photobleaching of FSSF, solutions of FSSF $(5,10$ and $20 \mu \mathrm{M})$ in $1 \mathrm{mM} \mathrm{GSSG}, 100 \mu \mathrm{M}$ NADPH, $100 \mathrm{mM} \mathrm{K}_{3} \mathrm{PO}_{4}, 1 \mathrm{mM}$ EDTA, pH 7.5 were prepared and the fluorescence intensity of each solution was measured at 10 min intervals for a total of $18 \mathrm{~h}$ (the same as for the GR experiments). The data obtained were then fitted to a first order reaction model using non-linear least squares regression with Dynafit and a rate constant $\left(\mathrm{k}_{\mathrm{pb} 2}\right)$ for the photobleaching of FSSF was calculated. The rate constant for photobleaching of FSH $\left(\mathrm{k}_{\mathrm{pb1}}\right)$ was determined separately by cleaving FSSF with DTT and will be discussed on subsequent pages. 


\subsubsection{Dynafit Script for Non-Linear Least Squares Regression Analysis of FSSF}

\section{Photobleaching}

[task]

$$
\text { data }=\text { progress }
$$

task $=$ fit

[mechanism]

FSSF ---> photobleached-FSSF : kpb2

[constants]

$$
\mathrm{kpb} 2=2 \mathrm{e}-006 ? ? \quad \text {; } \quad \text { Initial estimate }
$$

[responses]

$\mathrm{FSSF}=207 ?$

[progress]

directory ./glutathione/GR/data

extension txt

file 25uMFlu01UGR0uL | conc. FSSF $=25 ? \quad \mid$ delay $=90$

file 25uMFlu001UGR0uL | conc. FSSF $=25 ? \quad \mid$ delay $=420$

file 10uMFlu01UGR0uL | conc. FSSF $=10 ? \quad \mid$ delay $=90$

file $10 \mathrm{uMFlu001UGR0uL} \quad$ conc. FSSF $=10 ? \quad \mid$ delay $=420$

file 5uMFlu01UGR0uL $\mid$ conc. FSSF $=5 ? \quad \mid$ delay $=90$

file 5uMFlu001UGR0uL $\mid$ conc. FSSF $=5 ? \quad \mid$ delay $=420$

[output]

directory ./glutathione/GR/kpb2/output

[settings]

$<$ Marquardt $>$

Interrupt $=1000$

$<$ Constraints $>$

ConcError $=0.15 \quad$;Concentrations allowed to vary up to $15 \%$ to account for pipetting errors

[end] 
Table S-1. Fitted parameters from Dynafit analysis of FSSF photobleaching

\begin{tabular}{|c|c|c|c|c|c|}
\hline \multirow[t]{3}{*}{ Set } & Parameter & Initial & Fit & Error & $\%$ \\
\hline & $\mathrm{k}_{\mathrm{pb} 2}$ & $2 \mathrm{e}-006$ & $1.9705 \mathrm{e}-006$ & $4.06 \mathrm{e}-008$ & 2.1 \\
\hline & $\mathrm{r}_{\mathrm{FSSF}}$ & 207 & 178.424 & 0.153 & 0.1 \\
\hline 1 & [FSSF] & 25 & 21.3756 & 0.02325 & 0.1 \\
\hline 2 & [FSSF] & 25 & 23.8448 & 0.03152 & 0.1 \\
\hline 3 & [FSSF] & 10 & 9.90829 & 0.01848 & 0.2 \\
\hline 4 & {$[\mathrm{FSSF}]$} & 10 & 11.048 & 0.0235 & 0.2 \\
\hline 5 & [FSSF] & 5 & 4.79654 & 0.01788 & 0.4 \\
\hline 6 & {$[\mathrm{FSSF}]$} & 5 & 5.43827 & 0.01552 & 0.3 \\
\hline
\end{tabular}

Table S-2. 99\% confidence intervals for fitted parameters from Dynafit analysis of FSSF photobleaching

\begin{tabular}{|l|l|l||}
\hline \hline $\mathbf{K}_{\mathbf{p b 2}}$ & lower & upper \\
\hline standard error & $1.9299 \mathrm{e}-006$ & $2.0111 \mathrm{e}-006$ \\
\hline linear approximation & $1.8656 \mathrm{e}-006$ & $2.0753 \mathrm{e}-006$ \\
\hline exact intervals & $1.9407 \mathrm{e}-006$ & $2.0003 \mathrm{e}-006$ \\
\hline \hline
\end{tabular}




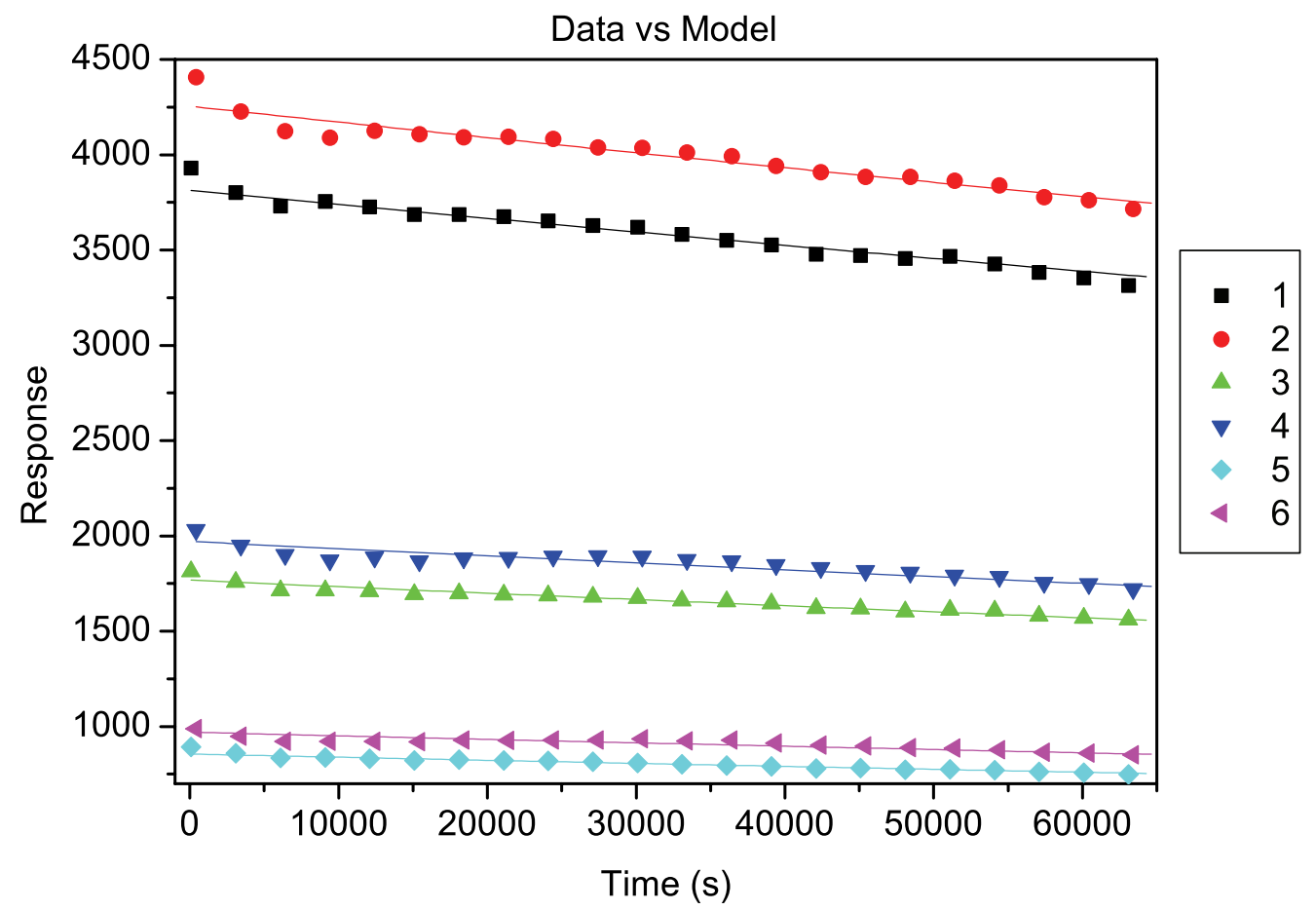

Figure S-3. Data vs Model plot from Dynafit analysis of FSSF photobleaching. Symbols represent measured data points, while lines represent the fitted model. Numbers in the legend refer to the data set numbers in Table S-1.

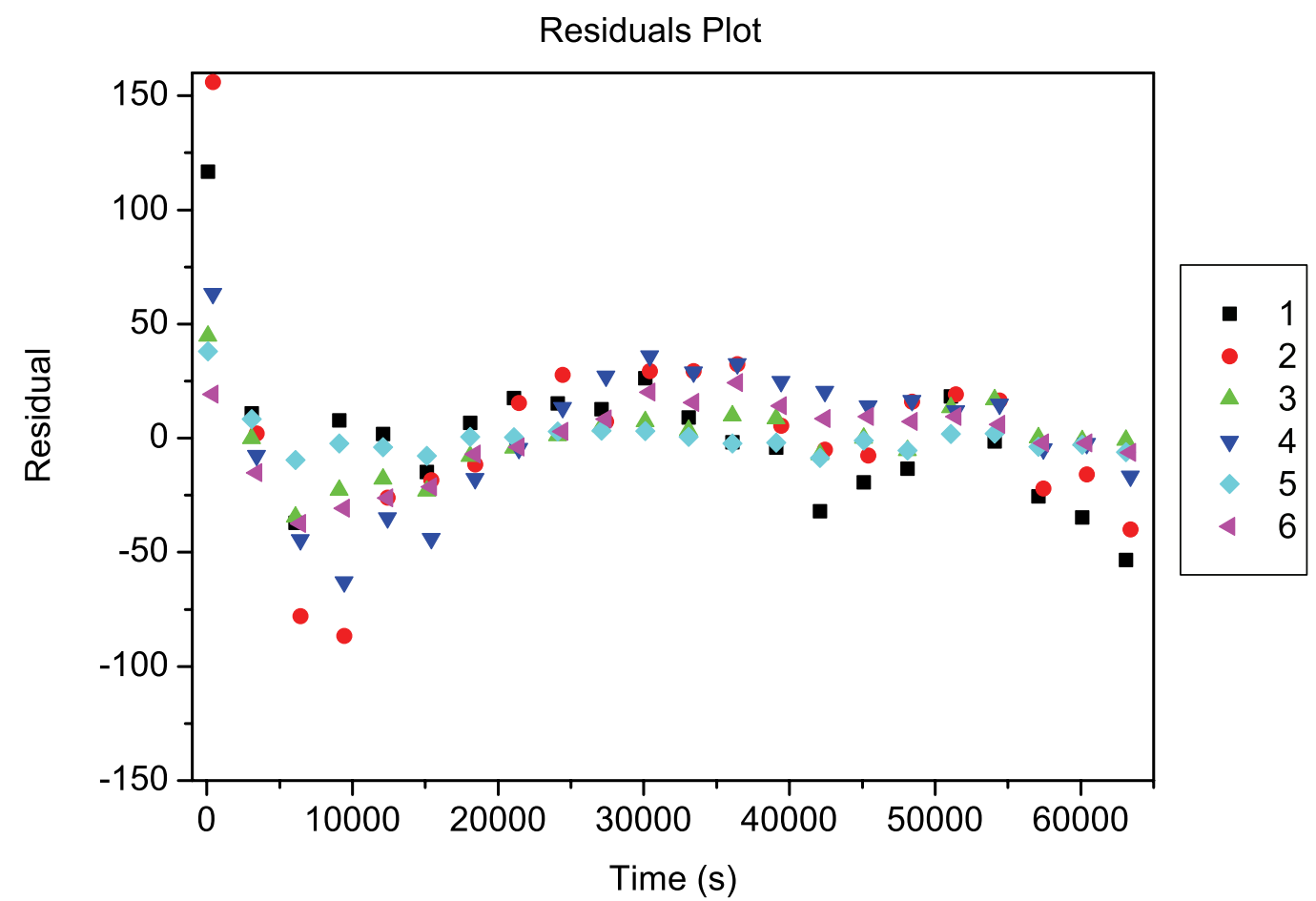

Figure S-4. Residual plot from Dynafit analysis of FSSF photobleaching. Numbers in the legend refer to the data set numbers in Table S-1. 


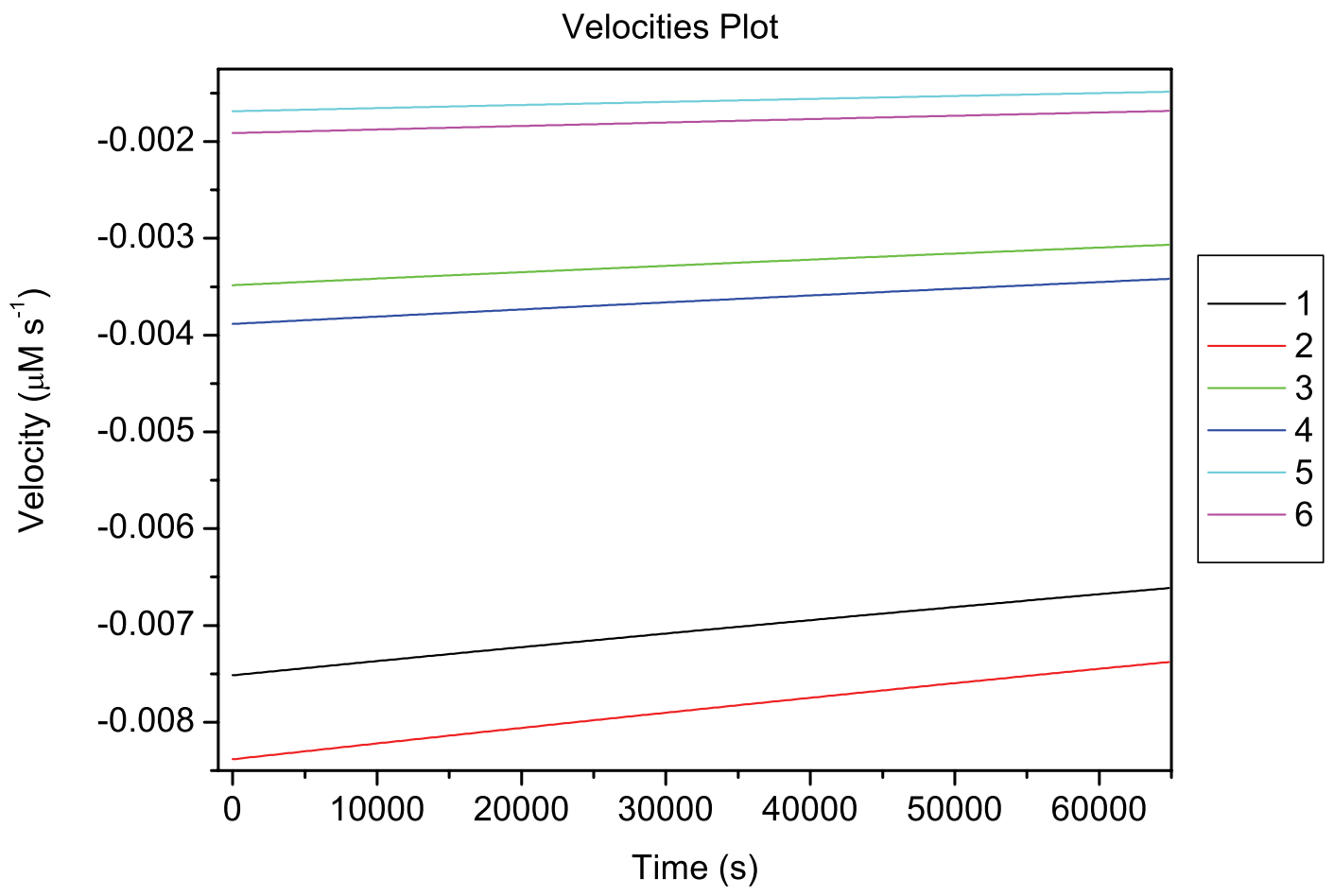

Figure S-5. Velocities plot from Dynafit analysis of FSSF photobleaching. Numbers in the legend refer to the data set numbers in Table S-1.

\subsubsection{Cleavage of FSSF by DTT}

Initially, a two-reaction model was used to fit the data obtained from the cleavage of FSSF by DTT - one reaction describing the actual cleavage of FSSF by DTT $\left(\mathrm{k}_{1}\right)$ and the other reaction accounting for the photobleaching of FSSF $\left(\mathrm{k}_{\mathrm{pb} 2}\right)$. The value of $\mathrm{k}_{\mathrm{pb} 2}$ was fixed to that obtained in the previous photobleaching experiment while the value of $\mathrm{k}_{1}$ was allowed to vary. Once an initial estimate for $\mathrm{k}_{1}$ was obtained, a third reaction was added to the model to account for photobleaching of FSH ( $\left.\mathrm{k}_{\mathrm{pb} 1}\right)$ and both $\mathrm{k}_{1}$ and $\mathrm{k}_{\mathrm{pb} 1}$ were allowed to vary to improve the overall fit.

This produced a much better fit for the reaction between our probe and DTT. Thus Figure S-6 has residuals an order of magnitude smaller than those of Figure S-2 (data not shown) where a simple one-phase exponential is used to calculate the response factor. 


\subsubsection{Dynafit Script for Non-Linear Least Squares Regression Analysis of FSSF}

\section{Cleavage by DTT}

[task]

data $=$ progress

task $=$ fit

[mechanism]

FSSF + DTT --> FSH + FSH + oxidized-DTT $\quad: \mathrm{k} 1$

FSH $\quad-->$ photobleached-FSH $\quad: \mathrm{kpb} 1$

FSSF $\quad-->$ photobleached-FSSF $\quad: \mathrm{kpb} 2$

[constants]

$\begin{array}{lll}\mathrm{k} 1 & =1 \mathrm{e}-007 ? ? & \\ \mathrm{kpb} 1 & =1 \mathrm{e}-005 ? ? & \end{array}$

[responses]

$\mathrm{FSH}=1600 ?$

$\mathrm{FSSF}=207 ?$

[progress]

directory ./glutathione/DTT/data

extension txt

file 10uMFlu10mMDTT

file 10uMFlu1mMDTT

file 10uMFlu01mMDTT

| conc. $\mathrm{FSSF}=10 ?, \quad \mathrm{DTT}=10000 ?$

| delay $=35$

conc. FSSF $=10 ?, \quad$ DTT $=1000 ? \quad \mid$ delay $=45$

conc. $\mathrm{FSSF}=10 ?, \quad \mathrm{DTT}=100 ? \quad \mid$ delay $=60$

file 1uMFlu10mMDTT

|conc. $\mathrm{FSSF}=1 ?, \quad \mathrm{DTT}=10000 ? \quad \mid$ delay $=30$

file 1uMFlu1mMDTT

conc. $\mathrm{FSSF}=1 ?, \quad \mathrm{DTT}=1000 ?$

delay $=45$

file 1uMFlu01mMDTT

conc. $\mathrm{FSSF}=1 ?, \quad \mathrm{DTT}=100 ?$

delay $=60$

file 01uMFlu10mMDTT

conc. $\mathrm{FSSF}=0.1 ?, \quad \mathrm{DTT}=10000 ?$

delay $=30$

file 01uMFlu1mMDTT

conc. $\mathrm{FSSF}=0.1 ?, \quad \mathrm{DTT}=1000$ ?

delay $=45$

file 01uMFlu01mMDTT

conc. $\mathrm{FSSF}=0.1 ?, \quad \mathrm{DTT}=100$ ?

delay $=60$

file 001uMFlu10mMDTT

conc. $\mathrm{FSSF}=0.01 ?, \mathrm{DTT}=10000 ?$

delay $=30$

file 001uMFlu1mMDTT

conc. $\mathrm{FSSF}=0.01 ?, \mathrm{DTT}=1000$ ?

delay $=45$

file 001uMFlu01mMDTT

conc. $\mathrm{FSSF}=0.01 ?, \mathrm{DTT}=100 ?$

delay $=60$

[output]

directory ./glutathione/DTT/output

[settings]

$<$ Marquardt $>$

Interrupt $=1000$

$<$ Constraints $>$

ConcError $=0.15 \quad$; Concentrations allowed to vary up to $15 \%$ to account for pipetting errors

[end] 
Table S-3. Fitted parameters from Dynafit analysis of FSSF Cleavage by DTT

\begin{tabular}{|c|c|c|c|c|c|}
\hline \multirow[t]{5}{*}{ Set } & Parameter & Initial & Fit & Error & $\%$ \\
\hline & $\mathrm{k}_{1}$ & $1 e-007$ & $1.11089 \mathrm{e}-007$ & $7.974 \mathrm{e}-011$ & 0.1 \\
\hline & $\mathrm{k}_{\mathrm{pb} 1}$ & $1 e-005$ & $9.07381 \mathrm{e}-006$ & $4.684 \mathrm{e}-008$ & 0.5 \\
\hline & $\mathrm{r}_{\mathrm{FSSF}}$ & 207 & 231.565 & 0.6776 & 0.3 \\
\hline & $\mathrm{r}_{\mathrm{FSH}}$ & 1600 & 1609.01 & 0.262 & 0.0 \\
\hline 1 & [FSSF] & 10 & 9.83172 & 0.00161 & 0.0 \\
\hline 1 & [DTT] & 10000 & 10719.3 & 12.29 & 0.1 \\
\hline 2 & [FSSF] & 10 & 10.4941 & 0.003616 & 0.0 \\
\hline 2 & [DTT] & 1000 & 1059.88 & 0.5668 & 0.1 \\
\hline 3 & [FSSF] & 10 & 10.9925 & 0.01525 & 0.1 \\
\hline 3 & [DTT] & 100 & 110 & 0.423 & 0.4 \\
\hline 4 & [FSSF $]$ & 1 & 1.1 & 0.002145 & 0.2 \\
\hline 4 & [DTT] & 10000 & 10171 & 107 & 1.1 \\
\hline 5 & [FSSF] & 1 & 1.1 & 0.003081 & 0.3 \\
\hline 5 & [DTT] & 1000 & 1095.3 & 5.109 & 0.5 \\
\hline 6 & [FSSF] & 1 & 1.1 & 0.01199 & 1.1 \\
\hline 6 & [DTT] & 100 & 110 & 3.361 & 3.1 \\
\hline 7 & [FSSF] & 0.1 & 0.10705 & 0.002191 & 2.0 \\
\hline 7 & [DTT] & 10000 & 10200 & 1120 & 11.0 \\
\hline 8 & [FSSF] & 0.1 & 0.11 & 0.003067 & 2.8 \\
\hline 8 & [DTT] & 1000 & 1100 & 51.19 & 4.7 \\
\hline 9 & [FSSF] & 0.1 & 0.11 & 0.01196 & 10.9 \\
\hline 9 & [DTT] & 100 & 110 & 33.63 & 30.6 \\
\hline 10 & [FSSF] & 0.01 & 0.011 & 0.002567 & 23.3 \\
\hline 10 & [DTT] & 10000 & 11000 & 13360 & 121.4 \\
\hline 11 & [FSSF] & 0.01 & 0.011 & 0.003069 & 27.9 \\
\hline 11 & [DTT] & 1000 & 1100 & 512.7 & 46.6 \\
\hline 12 & {$[\mathrm{FSSF}]$} & 0.01 & 0.011 & 0.01121 & 102 \\
\hline 12 & [DTT] & 100 & 110 & 293.4 & 266.7 \\
\hline
\end{tabular}

Table S-4. $99 \%$ confidence intervals for fitted parameters from Dynafit analysis of FSSF Cleavage by DTT 


\begin{tabular}{||l|l|l||}
\hline \hline $\mathbf{k}_{\mathbf{1}}$ & lower & upper \\
\hline standard error & $1.11009 \mathrm{e}-007$ & $1.11168 \mathrm{e}-007$ \\
\hline linear approximation & $1.10883 \mathrm{e}-007$ & $1.11294 \mathrm{e}-007$ \\
\hline exact intervals & $1.10975 \mathrm{e}-007$ & $1.11223 \mathrm{e}-007$ \\
\hline \hline
\end{tabular}

\begin{tabular}{||l|l|l||}
\hline \hline $\mathbf{k}_{\mathbf{p b 1}}$ & lower & upper \\
\hline standard error & $9.02698 \mathrm{e}-006$ & $9.12065 \mathrm{e}-006$ \\
\hline linear approximation & $8.95301 \mathrm{e}-006$ & $9.19462 \mathrm{e}-006$ \\
\hline exact intervals & $8.9779 \mathrm{e}-006$ & $9.1743 \mathrm{e}-006$ \\
\hline \hline
\end{tabular}

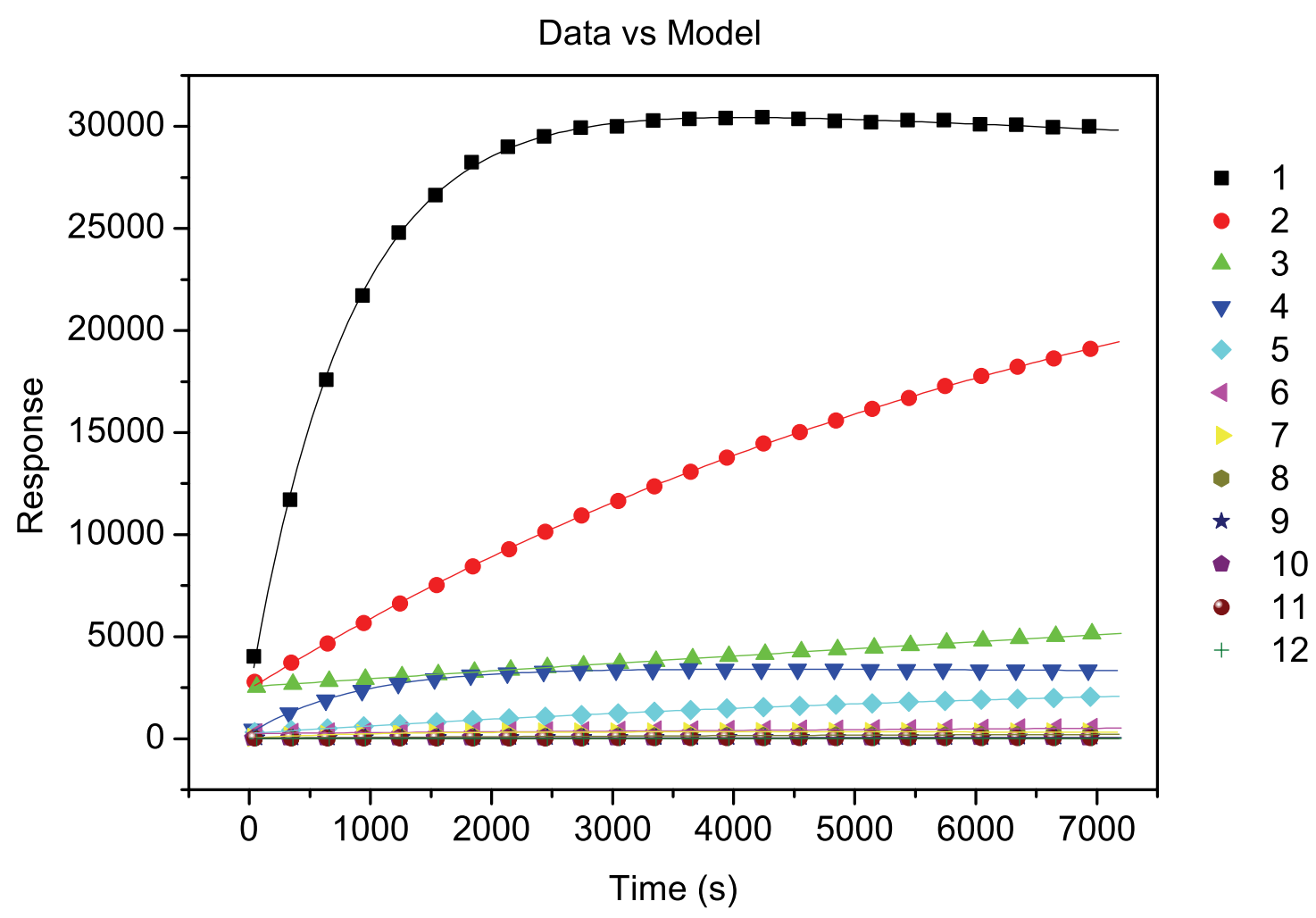

Figure S-6. Data vs Model plot from Dynafit analysis of FSSF cleavage by DTT. Symbols represent measured data points, while lines represent the fitted model. Numbers in the legend refer to the data set numbers in Table S-3. 


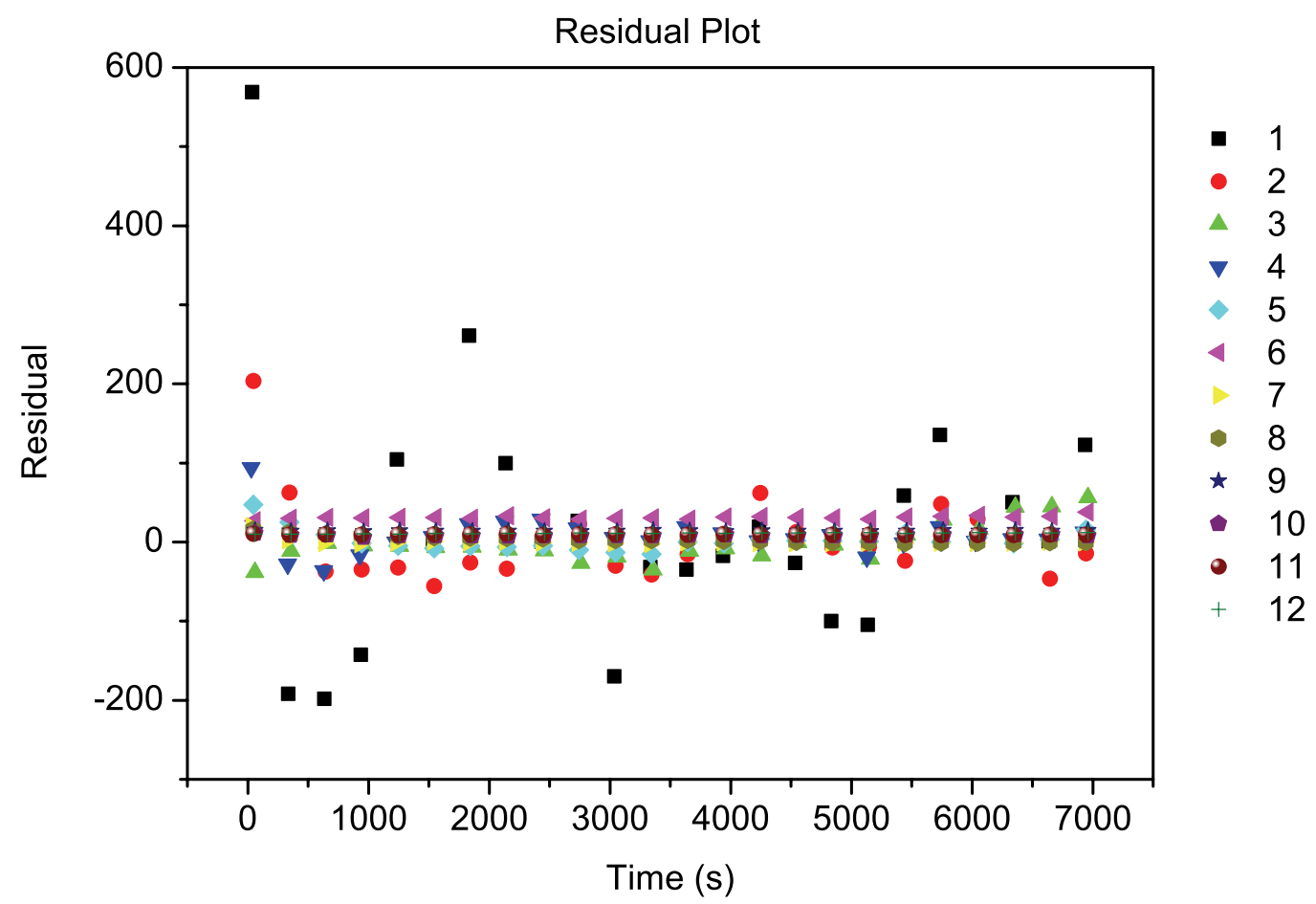

Figure S-7. Residual plot from Dynafit analysis of FSSF cleavage by DTT. Numbers in the legend refer to the data set numbers in Table S-3.

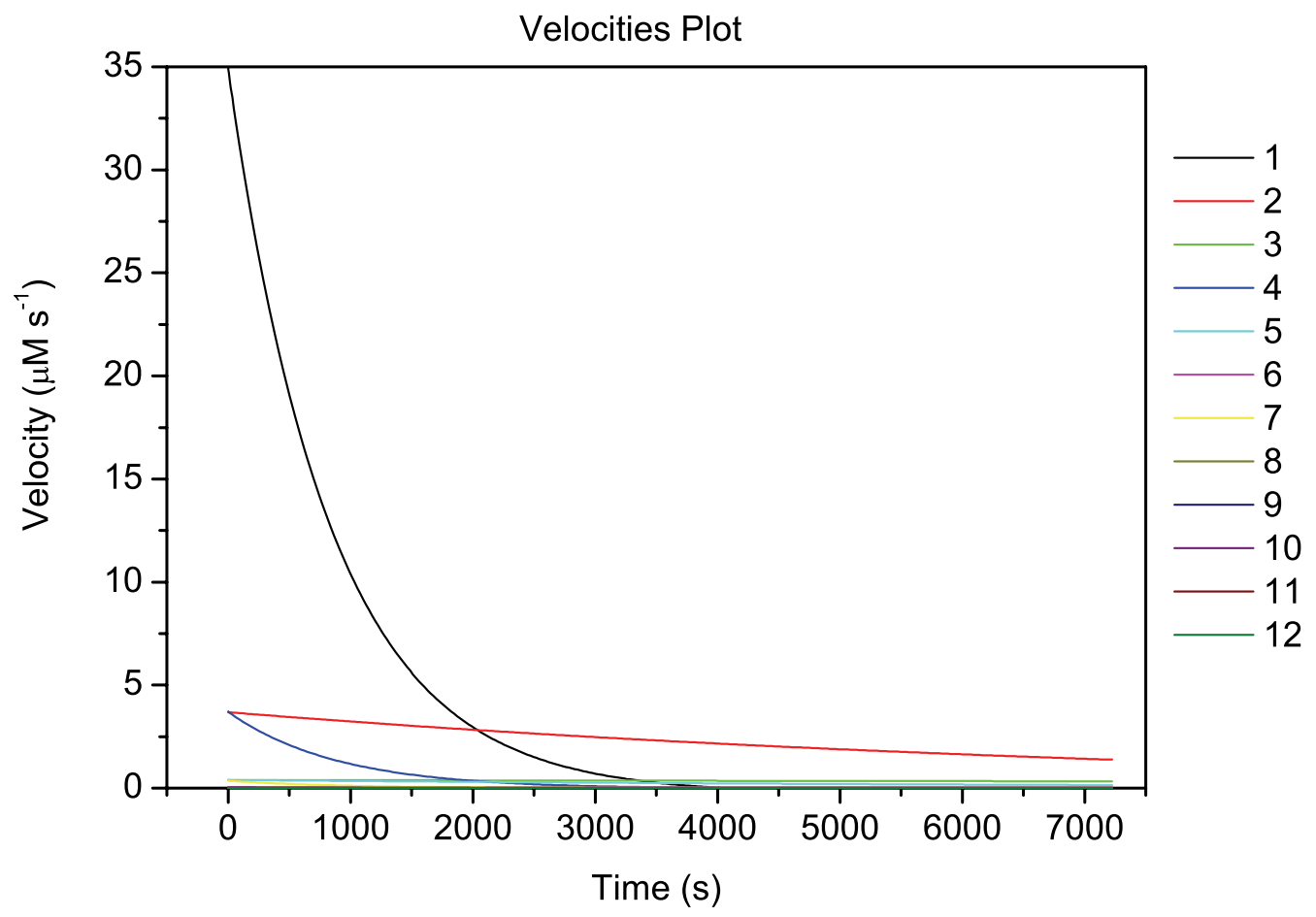

Figure S-8. Velocities plot from Dynafit analysis of FSSF cleavage by DTT. Numbers in the legend refer to the data set numbers in Table S-3. 


\subsubsection{Calculation of initial estimate for $k_{2}$}

The reaction of GSH (released by the action of GR on GSSG) with FSSF produces FSSG and FSH, both of which have equal fluorescence. FSH then immediately reacts with the excess of GSSG present to form a second molecule of FSSG, although this has no net effect on fluorescence. This is a complex process but can be adequately modeled as a pseudo-first order process that simply converts GSSG to two moles of FSSG. An initial estimate for $\mathrm{k}_{2}$ was obtained by using high concentrations of GR to generate a large excess of GSH, effectively eliminating the effect of enzyme concentration $\left(\mathrm{k}_{\mathrm{cat}}\right)$ from the calculations (Figure $\mathrm{S}-9$ ).

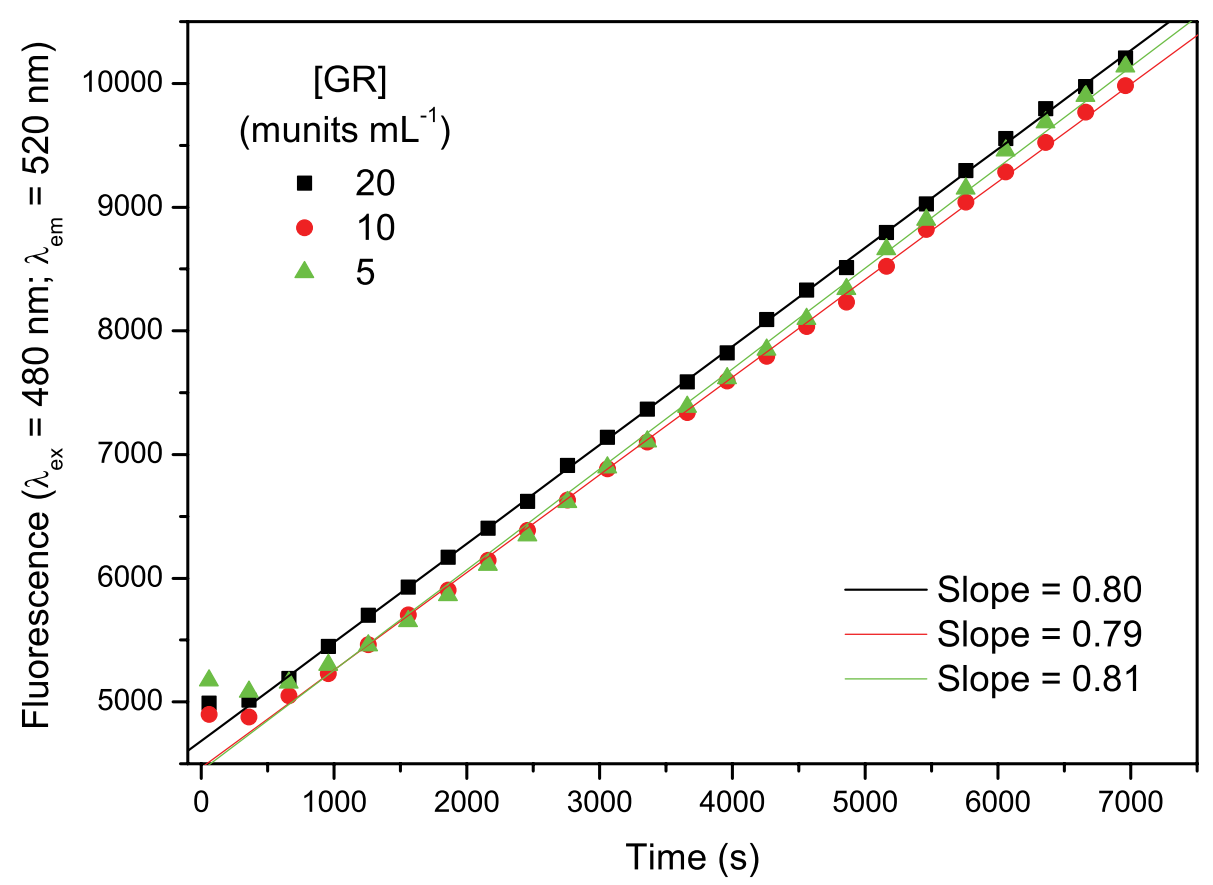

Figure S-9. Fluorescence intensity of $25 \mu \mathrm{M}$ FSSF, $1 \mathrm{mM} \mathrm{GSSG}, 100 \mu \mathrm{M}$ NADPH in $100 \mathrm{mM}$ $\mathrm{K}_{3} \mathrm{PO}_{4}, 1 \mathrm{mM}$ EDTA, $\mathrm{pH} 7.5$, after addition of 5, 10 and 20 munits $\mathrm{mL}^{-1}$ of GR at RT.

The average slope of the linear part of the curves $=0.8$ fluorescence units per second. As the formation of $1 \mu \mathrm{M}$ FSH generates 1600 fluorescence units, the reaction rate $=5 \times 10^{-4} \mu \mathrm{M} \mathrm{s}^{-1}$

$[\mathrm{GSH}]=2 \times[\mathrm{GSSG}]=2000 \mu \mathrm{M}$

$[\mathrm{FSSF}]=25 \mu \mathrm{M}$

Rate $=\mathrm{k}_{2}[\mathrm{GSH}]^{2}[\mathrm{FSSF}]$

$5 \times 10^{-4}=\mathrm{k}_{2}(2000)^{2}(25)$

$\mathrm{k}_{2}=5 \times 10^{-12} \mathrm{~L}^{2} \mu \mathrm{mol}^{-2} \mathrm{~s}^{-1}$ 


\subsubsection{Dynafit Script for Non-Linear Least Squares Regression Analysis of GR Assay}

[task]

data $=$ progress

task $=$ fit

[mechanism]

$\begin{array}{lll}\text { GSSG + GR } & -->\text { GSH + GSH + GR } & : \text { kcat } \\ \text { GSH + GSH + FSSF } & --->\text { FSSG + FSSG } & : \text { k2 } \\ \text { FSSG } & --->\text { photobleached-FSSG } & : \text { kpb1 } \\ \text { FSSF } & --->\text { photobleached-FSSF } & : \text { kpb2 } \\ \text { GR } & --->\text { denatured-GR } & : \text { kden }\end{array}$

[constants]

$\begin{array}{ll}\text { kcat } & =11 ? ? \\ \mathrm{k} 2 & =5 \mathrm{e}-012 ? ? \\ \mathrm{kpb} 1 & =9.07381 \mathrm{e}-006 \\ \mathrm{kpb} 2 & =1.9705 \mathrm{e}-006 \\ \text { kden } & =3 \mathrm{e}-005 ? ?\end{array}$

; Initial estimate determined from Figure S-9

; Fixed to value obtained from DTT experiment

; Fixed to value obtained from photobleaching experiment

; Enzyme inactivation optimized with $99 \%$ confidence interval

[responses]

$$
\mathrm{FSSG}=1600 ?, \quad \mathrm{FSSF}=207 ?
$$

[concentrations]

$$
\mathrm{GSSG}=1000
$$

[progress]

directory ./glutathione/GR/data extension txt

file 5uMFlu001UGR0uL

file 5uMFlu001UGR5uL

file 5uMFlu001UGR10uL

file 5uMFlu001UGR20uL

file 5uMFlu01UGR5uL

file 5uMFlu01UGR10uL

file 5uMFlu01UGR20uL

file 10uMFlu001UGR0uL

file 10uMFlu001UGR5uL

file 10uMFlu001UGR10uL

file 10uMFlu001UGR20uL

file 10uMFlu01UGR5uL

file 10uMFlu01UGR10uL

file 10uMFlu01UGR20uL

file 25uMFlu001UGR0uL

file 25uMFlu001UGR5uL

file 25uMFlu001UGR10uL

file 25uMFlu001UGR20uL

file 25uMFlu01UGR5uL

file $25 \mathrm{uMFlu} 01 \mathrm{UGR} 10 \mathrm{uL}$

file 25uMFlu01UGR20uL

$\begin{array}{ll}\mid \text { conc. } \mathrm{FSSF}=5 ?, \mathrm{GR}=0 & \mid \text { delay }=420 \\ \mid \text { conc. } \mathrm{FSSF}=5 ?, \mathrm{GR}=0.000002 ? & \mid \text { delay }=315 \\ \mid \text { conc. } \mathrm{FSSF}=5 ?, \mathrm{GR}=0.000004 ? & \mid \text { delay }=225 \\ \mid \text { conc. } \mathrm{FSSF}=5 ?, \mathrm{GR}=0.000008 ? & \mid \text { delay }=150 \\ \mid \text { conc. } \mathrm{FSSF}=5 ?, \mathrm{GR}=0.00002 ? & \mid \text { delay }=45 \\ \mid \text { conc. } \mathrm{FSSF}=5 ?, \mathrm{GR}=0.00004 ? & \mid \text { delay }=15 \\ \mid \text { conc. } \mathrm{FSSF}=5 ?, \mathrm{GR}=0.00008 ? & \mid \text { delay }=0 \\ \mid \text { conc. } \mathrm{FSSF}=10 ?, \mathrm{GR}=0 & \mid \text { delay }=420 \\ \mid \text { conc. } \mathrm{FSSF}=10 ?, \mathrm{GR}=0.000002 ? & \mid \text { delay }=315 \\ \mid \text { conc. FSSF }=10 ?, \mathrm{GR}=0.000004 ? & \mid \text { delay }=225 \\ \mid \text { conc. } \mathrm{FSSF}=10 ?, \mathrm{GR}=0.000008 ? & \mid \text { delay }=150 \\ \mid \text { conc. FSSF }=10 ?, \mathrm{GR}=0.00002 ? & \mid \text { delay }=45 \\ \mid \text { conc. } \mathrm{FSSF}=10 ?, \mathrm{GR}=0.00004 ? & \mid \text { delay }=15 \\ \mid \text { conc. } \mathrm{FSSF}=10 ?, \mathrm{GR}=0.00008 ? & \mid \text { delay }=0 \\ \mid \text { conc. } \mathrm{FSSF}=25 ?, \mathrm{GR}=0 & \mid \text { delay }=420 \\ \mid \text { conc. FSSF }=25 ?, \mathrm{GR}=0.000002 ? & \mid \text { delay }=315 \\ \mid \text { conc. FSSF }=25 ?, \mathrm{GR}=0.000004 ? & \mid \text { delay }=225 \\ \mid \text { conc. FSSF }=25 ?, \mathrm{GR}=0.000008 ? & \mid \text { delay }=150 \\ \mid \text { conc. } \mathrm{FSSF}=25 ?, \mathrm{GR}=0.00002 ? & \mid \text { delay }=45 \\ \mid \text { conc. } \mathrm{FSSF}=25 ?, \mathrm{GR}=0.00004 ? & \mid \text { delay }=15 \\ \mid \text { conc. } \mathrm{FSSF}=25 ?, \mathrm{GR}=0.00008 ? & \mid \text { delay }=0\end{array}$

[output]

directory ./glutathione/GR/output

[settings]

$<$ Marquardt $>$

Interrupt $=1000$

$<$ Constraints $>$

ConcError $=0.15 \quad$;Concentrations allowed to vary up to $15 \%$ to account for pipetting errors

[end] 
Table S-5. Fitted parameters from Dynafit analysis of GR Assay

\begin{tabular}{|c|c|c|c|c|c|}
\hline \multirow[t]{6}{*}{ Set } & Parameter & Initial & Fit & Error & $\%$ \\
\hline & $\mathrm{k}_{\text {cat }}$ & 11 & 11.787 & 0.03504 & 0.3 \\
\hline & $\mathrm{k}_{2}$ & $5 e-012$ & $4.3078 \mathrm{e}-012$ & $3.939 \mathrm{e}-015$ & 0.1 \\
\hline & $\mathrm{k}_{\text {den }}$ & $3 e-005$ & $3.05799 \mathrm{e}-005$ & $9.979 \mathrm{e}-008$ & 0.3 \\
\hline & $\mathrm{r}_{\mathrm{FSSF}}$ & 207 & 185.537 & 0.6688 & 0.4 \\
\hline & $\mathrm{r}_{\mathrm{FSSG}}$ & 1600 & 1252.49 & 0.4896 & 0.0 \\
\hline 1 & [GR] & $8 \mathrm{e}-005$ & $6.8 \mathrm{e}-005$ & $2.919 \mathrm{e}-006$ & 4.3 \\
\hline 1 & [FSSF] & 25 & 21.5275 & 0.04466 & 0.2 \\
\hline 2 & [GR] & $4 \mathrm{e}-005$ & $3.4 \mathrm{e}-005$ & $5.503 e-007$ & 1.6 \\
\hline 2 & [FSSF] & 25 & 21.3396 & 0.0333 & 0.2 \\
\hline 3 & [GR] & $2 \mathrm{e}-005$ & $1.94802 \mathrm{e}-005$ & $1.095 \mathrm{e}-007$ & 0.6 \\
\hline 3 & [FSSF] & 25 & 21.8753 & 0.02156 & 0.1 \\
\hline 4 & [GR] & $8 e-006$ & $8.25097 \mathrm{e}-006$ & $2.228 \mathrm{e}-008$ & 0.3 \\
\hline 4 & [FSSF] & 25 & 21.25 & 0.02148 & 0.1 \\
\hline 5 & [GR] & $4 \mathrm{e}-006$ & 4.20997e-006 & $1.031 \mathrm{e}-008$ & 0.2 \\
\hline 5 & {$[\mathrm{FSSF}]$} & 25 & 22.7022 & 0.03148 & 0.1 \\
\hline 6 & [GR] & $2 \mathrm{e}-006$ & $2.3 e-006$ & 7.7e-009 & 0.3 \\
\hline 6 & [FSSF] & 25 & 24.1363 & 0.05208 & 0.2 \\
\hline 7 & [FSSF] & 25 & 22.9304 & 0.1273 & 0.6 \\
\hline 8 & [GR] & $8 \mathrm{e}-005$ & $6.8 \mathrm{e}-005$ & $8.34 \mathrm{e}-006$ & 12.3 \\
\hline 8 & [FSSF $]$ & 10 & 10.011 & 0.06464 & 0.6 \\
\hline 9 & [GR] & $4 \mathrm{e}-005$ & $3.4 \mathrm{e}-005$ & $1.072 \mathrm{e}-006$ & 3.2 \\
\hline 9 & [FSSF] & 10 & 10.2263 & 0.03478 & 0.3 \\
\hline 10 & [GR] & $2 \mathrm{e}-005$ & $1.71399 \mathrm{e}-005$ & $1.478 \mathrm{e}-007$ & 0.9 \\
\hline 10 & [FSSF] & 10 & 10.7597 & 0.02104 & 0.2 \\
\hline 11 & [GR] & $8 e-006$ & $8.21207 \mathrm{e}-006$ & $4.024 \mathrm{e}-008$ & 0.5 \\
\hline 11 & [FSSF] & 10 & 9.24953 & 0.02174 & 0.2 \\
\hline 12 & [GR] & $4 e-006$ & $4.15684 \mathrm{e}-006$ & $1.768 \mathrm{e}-008$ & 0.4 \\
\hline 12 & [FSSF $]$ & 10 & 10.3055 & 0.03107 & 0.3 \\
\hline 13 & [GR] & $2 \mathrm{e}-006$ & $2.3 e-006$ & $1.407 \mathrm{e}-008$ & 0.6 \\
\hline 13 & [FSSF] & 10 & 11.5 & 0.05049 & 0.4 \\
\hline 14 & [FSSF] & 10 & 10.6244 & 0.08378 & 0.8 \\
\hline 15 & [GR] & $8 \mathrm{e}-005$ & $6.8 \mathrm{e}-005$ & $1.928 \mathrm{e}-005$ & 28.3 \\
\hline 15 & [FSSF] & 5 & 4.8683 & 0.07326 & 1.5 \\
\hline
\end{tabular}




\begin{tabular}{|l|l|l|l|l|l||}
\hline 16 & {$[\mathrm{GR}]$} & $4 \mathrm{e}-005$ & $3.4 \mathrm{e}-005$ & $1.757 \mathrm{e}-006$ & 5.2 \\
\hline 16 & {$[\mathrm{FSSF}]$} & 5 & 5.08412 & 0.02902 & 0.6 \\
\hline 17 & {$[\mathrm{GR}]$} & $2 \mathrm{e}-005$ & $1.7 \mathrm{e}-005$ & $2.641 \mathrm{e}-007$ & 1.6 \\
\hline 17 & {$[\mathrm{FSSF}]$} & 5 & 5.25433 & 0.01871 & 0.4 \\
\hline 18 & {$[\mathrm{GR}]$} & $8 \mathrm{e}-006$ & $8.59071 \mathrm{e}-006$ & $8.4 \mathrm{e}-008$ & 1.0 \\
\hline 18 & {$[\mathrm{FSSF}]$} & 5 & 4.43675 & 0.02014 & 0.5 \\
\hline 19 & {$[\mathrm{GR}]$} & $4 \mathrm{e}-006$ & $4.13491 \mathrm{e}-006$ & $3.363 \mathrm{e}-008$ & 0.8 \\
\hline 19 & {$[\mathrm{FSSF}]$} & 5 & 5.02587 & 0.02977 & 0.6 \\
\hline 20 & {$[\mathrm{GR}]$} & $2 \mathrm{e}-006$ & $2.3 \mathrm{e}-006$ & $6.362 \mathrm{e}-008$ & 2.8 \\
\hline 20 & {$[\mathrm{FSSF}]$} & 5 & 5.75 & 0.1072 & 1.9 \\
\hline 21 & {$[\mathrm{FSSF}]$} & 5 & 5.2297 & 0.06843 & 1.3 \\
\hline \hline
\end{tabular}

Table S-6. 99\% confidence intervals for fitted parameters from Dynafit analysis of GR assay

\begin{tabular}{|l|l|l||}
\hline \hline $\mathbf{k}_{\mathbf{c a t}}$ & lower & upper \\
\hline standard error & 11.7519 & 11.822 \\
\hline linear approximation & 11.6966 & 11.8773 \\
\hline exact intervals & 11.5878 & 11.5878 \\
\hline \hline
\end{tabular}

\begin{tabular}{|l|l|l|}
\hline \hline $\mathbf{k}_{\mathbf{2}}$ & lower & upper \\
\hline standard error & $4.30386 \mathrm{e}-012$ & $4.31174 \mathrm{e}-012$ \\
\hline linear approximation & $4.29765 \mathrm{e}-012$ & $4.31795 \mathrm{e}-012$ \\
\hline exact intervals & $4.29555 \mathrm{e}-012$ & $4.31688 \mathrm{e}-012$ \\
\hline \hline
\end{tabular}

\begin{tabular}{|l|l|l||}
\hline \hline $\mathbf{k}_{\mathbf{d e n}}$ & lower & upper \\
\hline standard error & $3.04801 \mathrm{e}-005$ & $3.06797 \mathrm{e}-005$ \\
\hline linear approximation & $3.03226 \mathrm{e}-005$ & $3.08372 \mathrm{e}-005$ \\
\hline exact intervals & $2.9211 \mathrm{e}-005$ & $3.1106 \mathrm{e}-005$ \\
\hline \hline
\end{tabular}




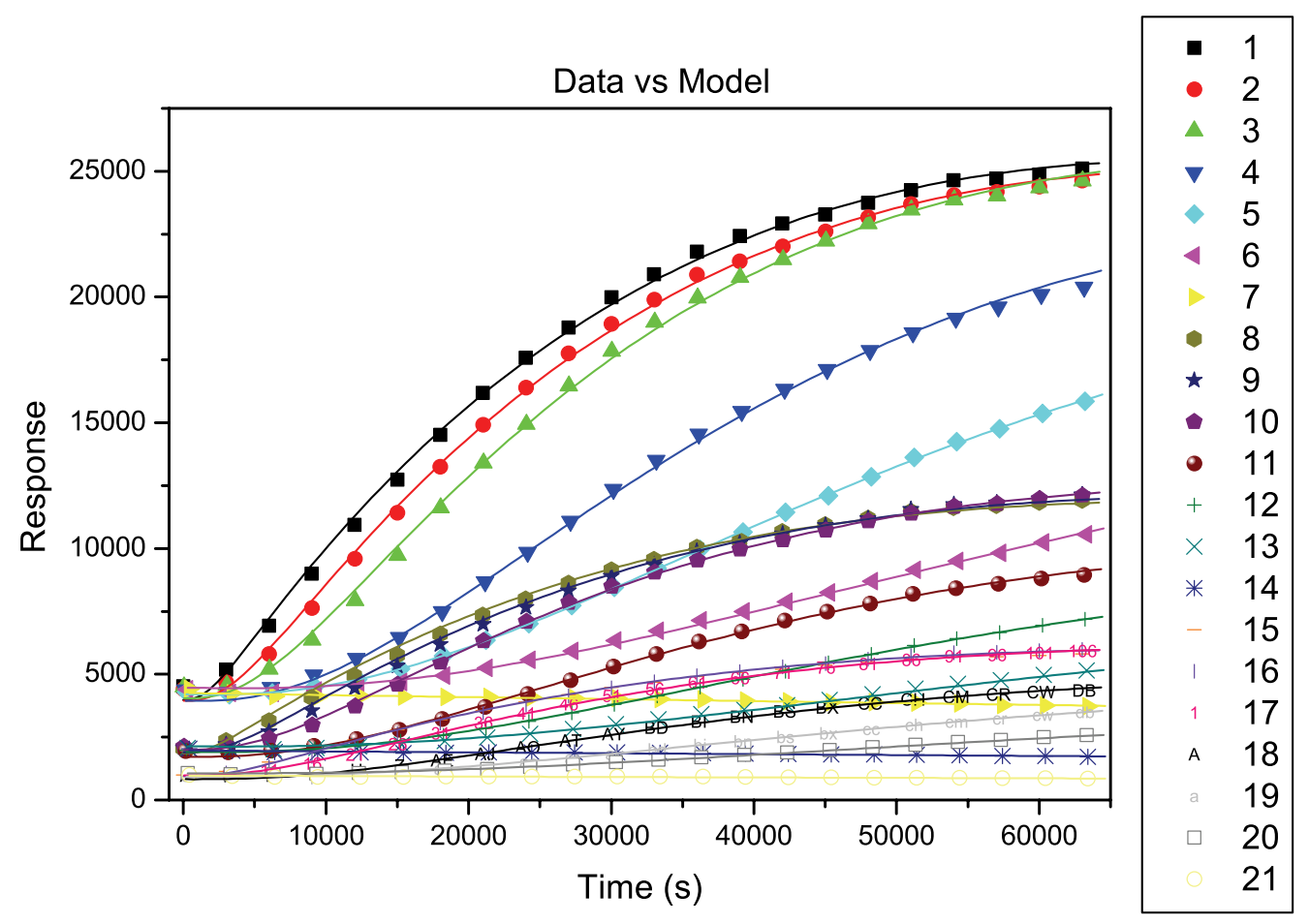

Figure S-10. Data vs Model plot from Dynafit analysis of GR assay. Symbols represent measured data points, while lines represent the fitted model. Numbers in the legend refer to the data set numbers in Table S-5.

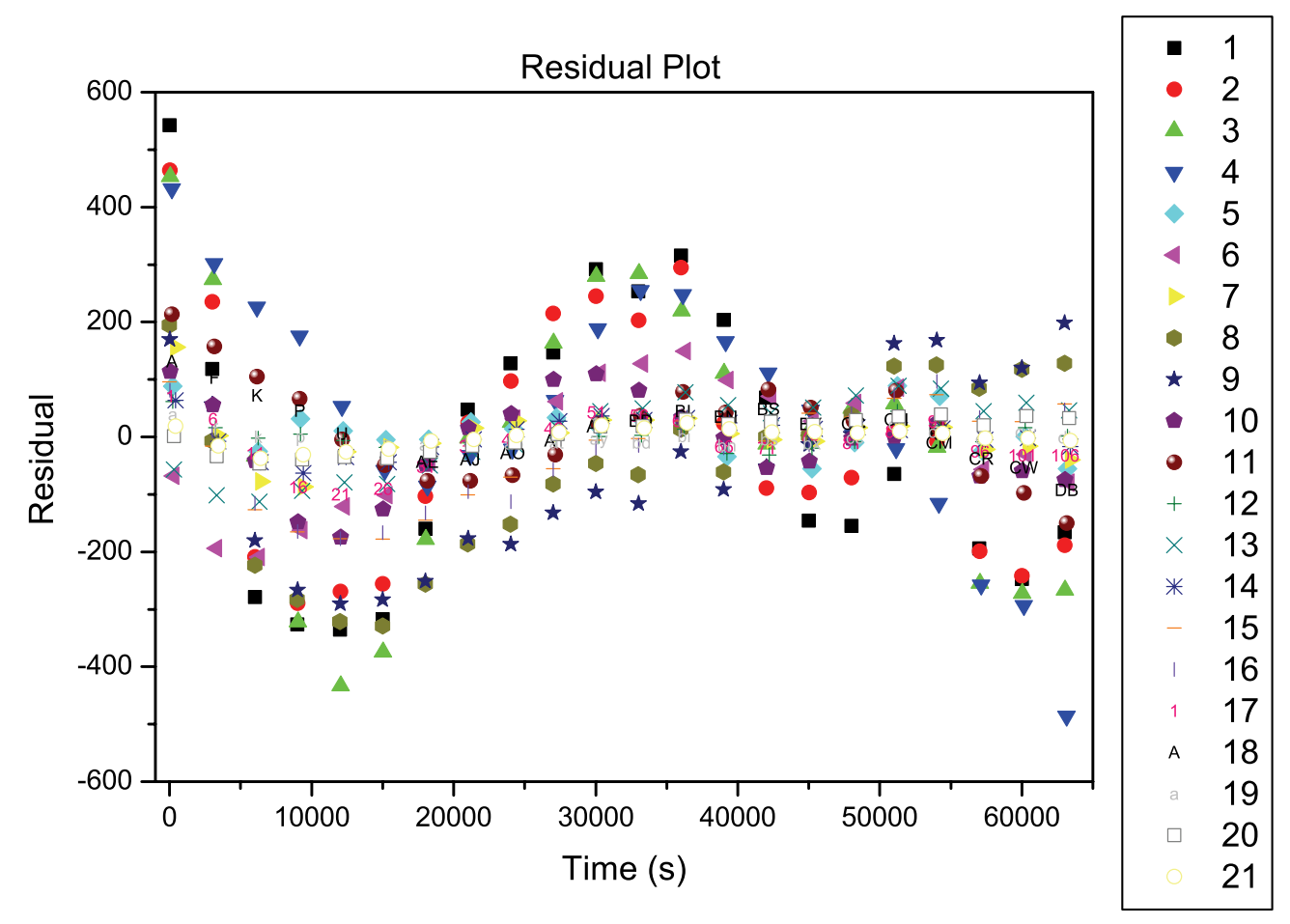

Figure S-11. Residual plot from Dynafit analysis of GR assay. Numbers in the legend refer to the data set numbers in Table S-5. 


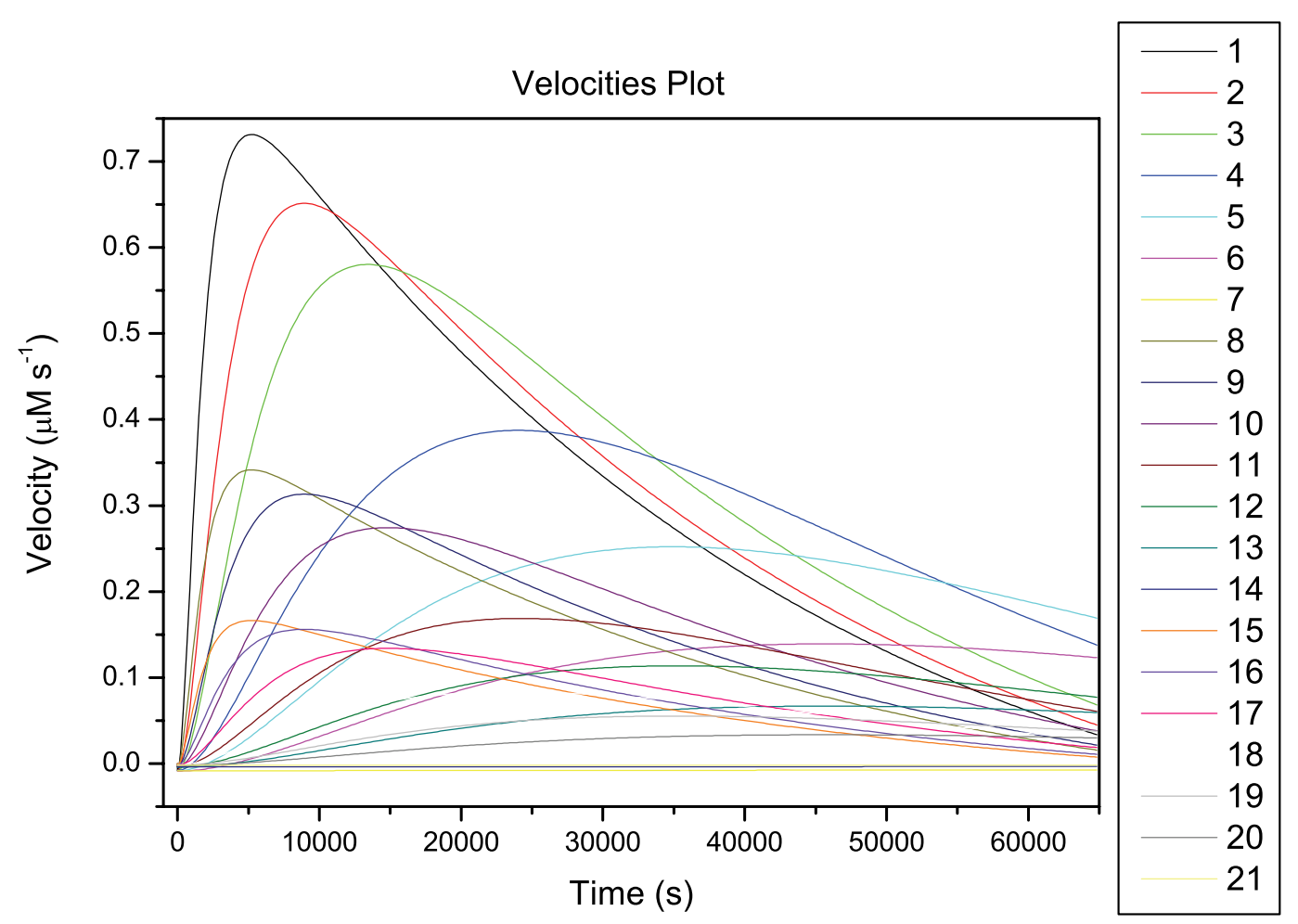

Figure S-12. Velocities plot from Dynafit analysis of GR assay. Numbers in the legend refer to the data set numbers in Table S-5.

\subsubsection{Comparison of fluorometric assay with commercial colorimetric (DTNB) GR assay}

To compare our fluorometric GR assay with the commonly used colorimetric assay based on DTNB, a commercially available assay kit from Sigma-Aldrich (USA) was used to construct a calibration plot for GR concentrations between 1-10 munits $\mathrm{mL}^{-1}$ (Figure S-13). The assay was performed exactly as described in the instructions supplied with the kit. The kit claims the concentration dependent enzymatic reaction is linear between 3 and 30 munits $\mathrm{mL}^{-1}$, while our fluorometric assay was linear between 0.05 and 2 munits $\mathrm{mL}^{-1}$, making our assay at least 60 times more sensitive and having a dynamic range at least one order of magnitude more than the colorimetric assay. The fluorometric assay is complementary to the Sigma-Aldrich assay in that it is useful in the lower range of GR activity but is also competitive in that GR assays suitable for the colorimetric assay can be diluted by up to $1000 \times$ and run on our fluorometric assay thereby diluting out possible interfering compounds by the same amount. 
Colorimetric Glutathione Reductase Assay using Commercial Kit

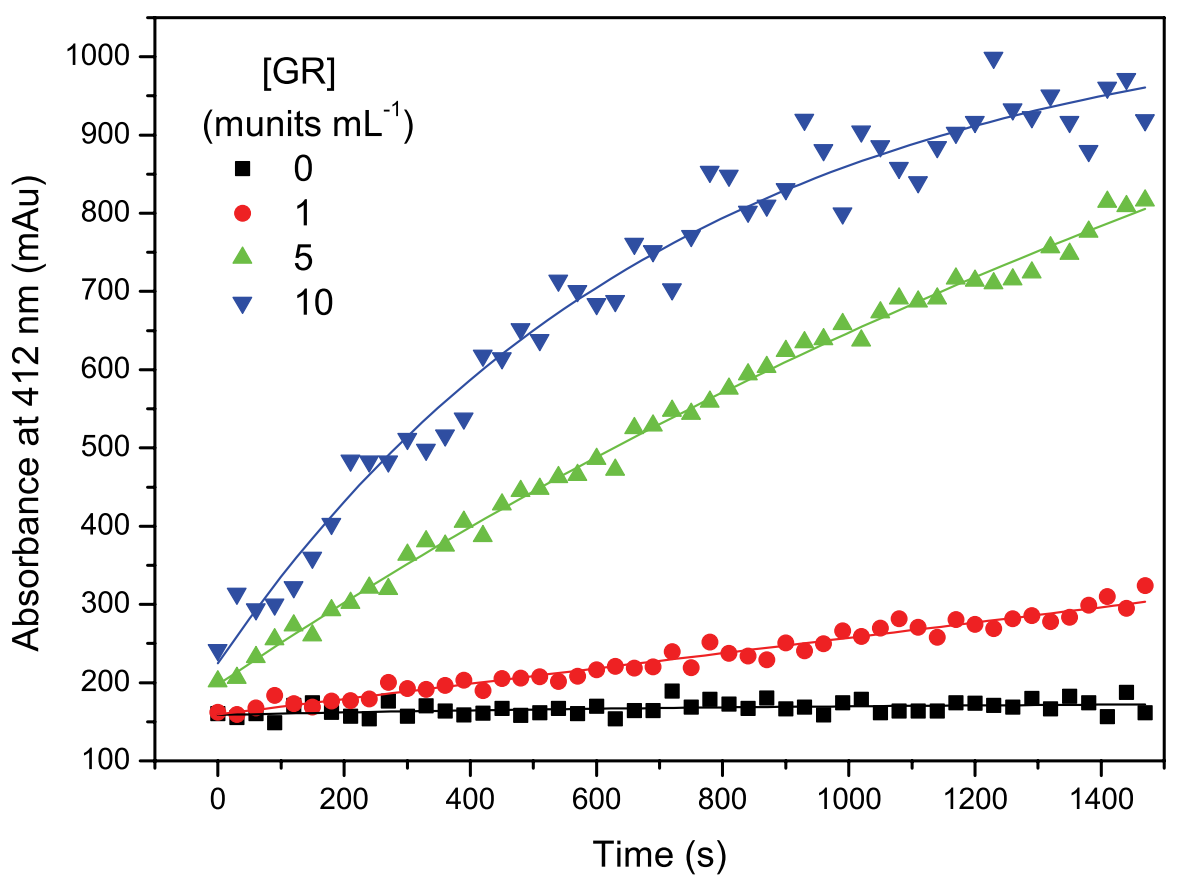

Figure S-13. Progress curves obtained from commercial colorimetric GR assay

\subsection{References}

(1) Spivak, D.; Shea, K.J. J. Org. Chem. 1999, 64, 4627-4634.

(2) Kuzmic, P. Anal. Biochem. 1996, 237, 260-273. 